\title{
Agromar [1936] e a(s) lingua(s): un discurso exemplificador do combate contra a diglosia
}

\author{
Goretti Sanmartín Rei \\ Universidade da Coruña
}

\begin{abstract}
Resumo:
Neste traballo realízase unha lectura desde unha perspectiva sociolingüística de Agromar, peza escrita por Filgueira Valverde e publicada, baixo o pseudónimo de J. Acuña, en 1936 cun interesante prólogo asinado polo pontevedrés. Para alén do propio texto da obra que ten sido obxecto de diversos achegamentos por parte de diferentes estudiosos do xénero teatral, procuramos tirar a máxima información do seu contorno máis inmediato, aqueles elementos que conforman o peritexto verbal do noso volume: título, subtítulo, prefacio, epílogo e notas. A funcionalidade bilingüe da farsa, a loita entre a aldea e a vila, o modelo de lingua elixido..., correspóndense cun esquema perfectamente deseñado polo autor en que cada peza serve ao proxecto doutrinal de transmitir, fundamentalmente á mocidade, actitudes de compromiso co país e co seu idioma.
\end{abstract}

\section{Palabras chave:}

Paratextos, diglosia, linguas da interaccion, conflito.

\begin{abstract}
:
This essay is based on a sociolinguistic aproach to Agromar by Xosé Filgueira Valverde, a play published with the pseudonym J. Acuña in 1936 and with an interesting preface signed by the author borned in Pontevedra. In addition to the text that has been analysed in different ways by many theatre critics, it was our main task the study of their verbal peritext: title, subtitle, preface, epilogue and notes. The bilingual functional character of the farce, the fight between village and small town, the choice of the langage... respond to a perfectly designed plan with the aim of trasmitting, mainly to the youth, obligations with the country and its language.
\end{abstract}

Key words:

Paratexts, diglossia, languages of interaction, conflict.

\section{Introdución}

A importancia dos elementos paratextuais incluídos na "primeira farsa para rapaces escrita en galego de que se ten noticia" (Carballo Calero 1981: 740), a peza 
Agromar asinada por J. Acuña e prologada por Filgueira Valverde, en realidade a mesma persoa, fixeron que volvésemos tamén a nosa ollada sobre o conxunto desta obra, pouco considerada nos estudos teatrais, ora polo seu didactismo ideoloxizante, ora por se autodefinir de maneira restritiva ao indicar seren os destinatarios ideais un único segmento da poboación, a xente nova, referente pouco frecuente no momento da súa publicación (1936) en calquera dos xéneros literarios desenvolvidos en galego naquela altura. Máis aínda, esta mocidade ten de se sentir vinculada, obrigatoriamente, ao mundo rural ${ }^{1}$, pois a intención é aloumiñar a súa enxebreza, algo só posíbel con quen parte desa tradición como aquela en que reside a alma galega. De feito, os rapaces da aldea vanse opor sempre aos da vila, e esa dicotomía vai ser suxerida tamén como posíbel título do epílogo se este se representar de maneira independente:

O remate, por enxempro, pode porse solto, como obra de burlas e co tiduo 'Leria do señorito da vila co rapás da aldeia'. Ou ser feito como prólogo, no escomenzo, de xeito que a farsa sexa o desenrolo das cousas que nos sorpenderon nel, se desta maña pode gorentar mais aos actores i-a sua xente, afeita xa á tecnica do teatro (Acuña 1936: 17).

Porén, coidamos que non pode enmarcarse esta obra no teatro de carácter infantil como se ten feito nalgunha ocasión (Riobó 2000: 28), sobre todo se concibimos este como aquel dirixido aos cativos e cativas, especialmente aos de menor idade, senón no teatro didáctico con intención de modificar a realidade inserido ou relacionado directamente cun proxecto educativo da mocidade galega, aquel dirixido por Álvaro das Casas, os agrupamentos Ultreya. Á coincidencia da data en que a peza é concebida coa $1^{\mathrm{a}}$ Xeira da "Misión Biolóxica de Galiza" (aspecto sobre o que volveremos), únense as similitudes coas ideas expresadas no Decálogo desta organización (véxase Nós 98: 33, 15-II-1932), sobre todo cos apartados I, IV, VI, VII e IX. Se atendermos ao texto que precede a obra sob o título de "Representación", veremos que do que se trata é de facer participar os rapaces, sendo estes elementos activos no desenvolvemento dramático, mudando elementos ou organizándoos doutro xeito ao asumiren a peza como a descrición dunha parte da realidade que todos coñecen:

Ás veces comprirá facer mais sinxela toda a obra; ás veces, crarexala con engádegas; ás veces deixar que os rapaces fagan a farsa de seu; o mestre a rexeitar, a escolmar, a compór cas mesmas ideias dos cativos, deica facer unha farsa nova (Acuña 1936: 17).

\footnotetext{
1 “A aldea Diol-a dea" (Filgueira Valverde 1936a: 13) é un desideratum que paira sobre toda a obra, claramente orientada a demostrar as virtudes do agro e a necesidade de se fusionaren co rus aqueles empeñados en levar a cabo a rexeneración espiritual da Galiza.
} 
Estamos, neste sentido, perante un texto que pretende porse ao servizo da loita galeguista, máis un instrumento de propaganda e de chamamento á mobilización² desde a perspectiva neotradicionalista defendida por Filgueira Valverde. Lembremos que este é un dos seguidores das teorías de Antón Losada Diéguez, doutrina que comparte con Otero Pedrayo ou Risco e caracterizada, segundo Beramendi / Núñez Seixas (1995: 100-110), por diferentes cuestións, de entre as que cómpre salientar a concepción católica do mundo ${ }^{3}$ e o enfrontamento entre tradición e modernidade ${ }^{4}$.

A nosa intención é ofrecer unha lectura da obra que non obvie os paratextos que a rodean, integrándoos na procura dun significado máis completo, algo que é imprescindíbel para a historia da literatura e para a contextualización da peza, entendendo esta como un sistema semiótico de significación e de comunicación ${ }^{5}$. Reducirmos o texto a aquel que é xa da obra, sen estabelecer o necesario diálogo previo con aqueles elementos que primeiro se nos apresentan, supón, paradoxalmente $^{6}$, coutar as posibilidades de interpretación do mesmo ao arredar unha das visións máis acaídas, pois unha das funcións básicas dos elementos paratextuais é favorecer unha "boa" lectura (Genette 1987: 183).

2 O propio prologuista di que a peza é "de senso social" (Filgueira Valverde 1936a: 10) con intención dun "trascender apoloxético do enxempro" (Filgueira Valverde 1936a: 9). A función é, pois, semellante á expresada por outros autores, como Antón Vilar Ponte en Almas mortas, cuxo texto prologal ten a pretensión de xustificar a exposición en forma de teatro do que enunciado nun libro doutrinal non chegaría máis que a unha reducida parte daqueles a quen vai dirixida a mensaxe: "Os temas que alumeo, n'un libro doutrinal non chegarían craramentes á todos. Mentres que asina, en xeito de novela dialogada, drento d'un sintetismo vulgare, o mais real posibre, comprenderánnos e discutiránnos cantos me leian. O que compre é que ninguén se sinta molesto pol-o que se dí n'esta patriótica farsada, nova, en algo do que trata, nas letras peninsuares. A esceución pode acoller á cantos queiran. Óllese, pois, cada un frente â regra xeneral. ¡Son chegádol-os tempos de facermos enxámen de concencia tódol-os bôs galegos! Y-eu dígovos que teño "americanos" na familia, e que eu mesmo fun "americano" (Villar Ponte 1922).

3 Lembremos as críticas de Filgueira ás obras que se desviaban deste criterio, como a que Pérez Parallé apresenta co título de Pepa Andrea. Novela iñota de Pedro Guimarey esceificada por J. Pérez Parallé: "Pedro Guimarey é descoñecido nas letras galegas, Pérez Parallé, non. No noso ficheiro aparez pol-o menos con tres traballos galegos pubricados nas páxinas de "Abrente", o orgao dos "Luises" de Compostela, fai uns cinco anos. A inspiración de "Pepa Andrea" rifa de cheo ca tónica relixiosa de aqueles poemas. E son precisamente aqueles poemas os que nos moven a ocuparnos desta obra. Porque a sona católica do autor pode levar a engano os lectores. E porque compre que os lectores lembremos tamén ao autor o seu verdadeiro camiño" (A[cuña] 1933a: 176).

4 Contradición de difícil resolución, que neste caso podemos exemplificar nos elementos que irrompen no mundo labrego de man do señorito da Coruña no epílogo final: a referencia aos cabarés, o deporte representado no tenis, as tanguistas, etc.

5 Favorecendo neste sentido unha utilización didáctica da obra como unha rede complexa e interrelacionada de significados, algo que xa ten sido sinalado con outras exemplificacións (Nogueira 1997: 261-273).

6 Pois en xeral os paratextos impoñen (ou condicionan) unha determinada lectura das obras ao reducir o coeficiente de liberdade semiótica do receptor.

7 No sentido daquela desexada polo emisor da mensaxe. 
Mais, vaiamos ao cerne da obra. Agromar representa con claridade a tendencia daqueles que defendían como predominante o valor da aldea no ser galego, os enxebristas ou ruralistas, utilizando denominacións de grande valor simbólico. Nese sentido, Filgueira achégase ao posicionamento de Antón Vilar Ponte ou Otero Pedrayo, observándose afinidades claras entre a personaxe de "Nito" e Adrián Solovio, feito salientado nas escasas referencias que esta obra ocupa nos manuais e nas historias de literatura galega (Bernárdez / Ínsua / Millán Otero / Rei Romeu / Tato Fontaíña 2001: 132), na maioría dos casos prescindindo da relevancia da instancia prologal. Unha lectura clarificadora da peza achámola en Rabunhal (1994: 222-223), quen obvia calquera comentario sobre o texto prefacial. Como tantas outras veces, é, do noso punto de vista, Carballo Calero quen ofrece unha mellor descrición do texto ao incluír importantes valoracións e abrir novos camiños de investigación:

Firmado J. Acuña, cun prólogo asinado cos seus propios apelidos, publicóu Filgueira Valverde unha peza de teatro para rapaces titulada Agromar. Os persoaxes da mesma -todos masculinos- son nenos ou mozos, agás o médico don Enrique. Dividida en dous "lances" e un "remate", é unha peza didáctica, orientada a defender e fomentar os valores da auténtica Galicia rural perante os falsos valores dunha cultura vilega mimética e esóxena. Opóñense "os mociños da aldea" a "os pitos da vila". Un daquéles transfunde o seu sangue a un déstes, ferido en accidente de tráfico; e co novo sangue o Nito señorito de vila transfórmase en mozo de aldea. A literariedade da peza é puramente estormental, pois só pretende servir á finalidade práctica que move ao autor. Mais éste, que contrasta a fala auténtica dos aldeáns coa xiria automatizada dos señoritos, percuróu e conseguiu que aquéles falasen un galego non por depurado menos vivaz e espontáneo (Carballo Calero 1981: 740).

O valor instrumental e o carácter pedagóxico que cae no maniqueísmo, por unha simplificación e un reducionismo difíceis de solventar nunha obra cuxa finalidade principal é ofrecer un ideal á mocidade, é xa anotado polo prologuista, quen, como é habitual, advirte das pexas que probabelmente se lle aporán á obra, defendéndose previamente das acusacións que lle serán formuladas:

Si os cativos precisan un arte seu -e pois un teatro- é porque, máis achegados á fonte da vida, sinten máis fonda a chamada do ben i-a magoa da falsía. Os nenos piden que agarimemos a sua enxebreza e que lles demos un ideal. E compre facelo, mesmo en xogos de bandos e símbolos, como llo dá "Agromar" (Filgueira Valverde 1936a: 13).

Reparemos en que neste caso a captatio benevolentiae é exercida a través do tópico da modestia (que terá diversas manifestacións no texto prefacial), rompendo coa habitual gabanza da obra e autor propia dos prólogos alógrafos.

Se o tema da rexeneración de Nito a través do sangue doado por Xelo lembra a problemática lingüística de Maxina, cuxa lingua viña determinada obrigatoriamente 
pola clase social a que pertencía, a ideoloxía tradicionalista, que ve na aldea a autenticidade e os valores necesarios para salvar o país, aparece agora superposta dun elemento novidoso, o representado polo médico, identificado claramente co sector representado polo galeguismo, único capaz de se fusionar co ser galego. Como ten analizado Beramendi para a época que nos ocupa:

O galego por excelencia, o portador dos caracteres básicos do Volksgeist é o labrego e, en menor medida, o mariñeiro (debuxos de Castelao, desenvolvemento dos estudios etnográficos, literatura populista), ese pobo traballador que sofre como ninguén as consecuencias do atraso económico, da negación da súa linguacultura e dos mecanismos de dominación dun sistema político clientelista, centralista e autoritario (Beramendi 1999: 18).

Un determinismo social inmobilista provoca que a posibilidade de redención na Terra asente sobre esa nova caste de persoas que se acredita que están a xurdir, a fidalguía rexenerada ou as clases medias comprometidas, pois, a pesar das fortes mudanzas de comportamentos descritas na peza e do achegamento entre "labregos" e "señoritos", o papel dos primeiros (representados por Xelo), e dos segundos (encabezados por D. Enrique e Nito), mantén as diferenzas de clase nun esquema claramente conservador:

D. Enrique: Xa o ouces. A aldeia pide que estudiedes o que os probes non poden estudiar. A nosa Terra pide inxenieros que sepan do millo e das patacas, das doenzas das prantas e da mellora do gando, do mel, do viño, dos piñeiros... de todalas cousas que a nosa grande irmán, a Terra, cría.

Nito: E Xelo?

Xelo: Xelo sementará o teu millo i-as tuas patacas, e ollará pol-as prantas, e polos piñeiros, e pol-o gando que tí traias pra nós; Xelo non deixa o sacho (Acuña 1936: 74).

A explicación dos diferentes criterios utilizados para un e para outro foi enunciada con anterioridade, cando Nito insiste en que Xelo debe estudar e este sente que ao facer iso acabaría afastándose da súa clase social:

[...] teño a seguranza de que este vivir señor me arredaría da Terra. Despois... sería como os amigos de Nito, perdida a i-alma na troula do señorío (Acuña 1936: 68).

No fondo latexa a imposibilidade de saír do círculo e de rachar coas diferenzas sociais, estabelecéndose unha alianza baseada na confianza mutua, mais onde cada quen serve, segundo a súa condición, ao país ${ }^{8}$. Velaí o desenlace final, pois así remata en realidade

8 Algo que se entende como perfectamente compatíbel coa penúltima das leis do Decálogo ultreiano: "Porque soño n-un porvir de verdadeira fraternidade, farei que por rente de min se xunten todol-os rapaces galegos pra que o día de mañán non nos afasten prexuicios de caste". 
a obra, xa que a escena que se desenvolve a seguir é considerada unha abrazadeira final, unha síntese ou un anticipo, dependendo do lugar escollido para a súa interpretación:

Xelo: A miña man labrega pra adeprenderte a choutar valados, o meu legón pra que o teu brazo abra o rego dos milleirás novos, a ledicia da miña amistade pra uns meses de vivir paisán, e unha aperta, que luxe ca miña roupa empoeirada do traballo o teu traxe de señorito... Que levas sangue meu! (Acuña 1936: 75).

A coincidencia é absoluta con aqueles postulados que vían no campesiñado a única clase social que podía garantir as esencias nacionais e que encarnaba as virtudes tradicionais. Para se converter ao nacionalismo, só precisarían a axuda das clases ilustradas, que podería rematar por resucitar, como Otero desexaba, o liderato social da vella fidalguía (Cabo Villaverde 1999: 293-294).

Mais se Carballo acerta perfectamente na súa descrición do fondo ideolóxico e da intencionalidade da obra, non menos relevantes son as palabras que dedica á lingua da obra. Dun coidado e depuración que a achegan á utilizada na actualidade, sen a excesiva artificiosidade con que outros autores fuxiron do español, o texto consegue ofrecer un idioma apto para a representación teatral, contradicindo a idea das "verbas limiares" en que Filgueira declara que "Galicia non é terra de dramáticas", aludindo á escasa tradición existente contra a que loitaron algunhas das persoas vinculadas ás Irmandades. O texto ofrece tamén unha interesante alternancia de códigos, neste caso plenamente xustificada no carácter didáctico da peza, cuxo sentido sería incomprensíbel nunha obra totalmente monolingüe. A fuxida da identificación entre falar galego e provocar o riso e a inversión total desta situación no remate ao ser o noso idioma o empregado polas personaxes cultas e pertencentes ás clases altas, buscan xustamente a ruptura do horizonte de expectativas dun receptor que non pode máis que se interrogar sobre a realidade da situación alí descrita. O contraste con boa parte dos textos teatrais bilingües anteriores en que se reflectía un esquema diglósico polos temas ou a clase social dos protagonistas é evidente, mesmo coa intencionalidade de procurar outros referentes para un público afeito a un modelo que pasaba pola invisibilidade do noso idioma ou pola súa condena ao enclaustramento e á redución a un gueto. Non esquece Filgueira incluír un modelo de español claramente agalegado que todo o público sentirá como afastado da norma habitual dos contextos formais, na procura da ridiculización do seu emprego.

Outras suxestións de interese fálannos da ausencia de personaxes femininas, algo que é totalmente consecuente coa realidade que o autor quere mostrar, onde as mulleres son o pano de fondo invisíbel ou relegado a unha coparticipación dirixida en que todo está determinado con anterioridade. Se tanto as Irmandades, Nós ou o Seminario de Estudos Galegos foron proxectos claramente masculinos, non menos o foron os Ultreya e os grupos de estudantes que participaron como Filgueira na "Misión Biolóxica" de Galiza. Alén diso, a obra está claramente destinada aos varóns, pois as 
mulleres recibiron habitualmente mensaxes ben diferenciadas ${ }^{9}$, e mesmo Filgueira ten expresado ese sentimento de desazón que lles producía ter que dar explicacións ás rapazas na súa lembranza dunha lección de Lousada Diéguez, o seu mestre ${ }^{10}$. Realmente a contraposición vai moito máis lonxe, confrontando o balbordo das nenas ao silencio dos rapaces, a súa actividade mental e espiritual á pasividade da muller, sempre subordinada ao varón. En definitiva, observamos o que non se pode definir máis que como desprezo pola muller, mesmo adubiado coa típica sublimación:

Despois o mestre entra mais fondo, en nós. Quen lembrara aquel eloxio da castidá vivificante, aquel endereitarnos cara un ideal, cara unha afición, cara unha constante actividá, pra gardar a nosa mocedade! Despois, a gabanza da muller, aquela beleza en que él adouraba a Dios, a fermosa dona, a irmán, a nai que tiñamos de lembrar frente ôs que soio a buscan como instrumento de pracer.

Logo o mestre escomenza paseniño a exposizón da lección. Ô afondare no que sempre tratamos ledamente quéimanos a i-alma. Porqué teríamos tomado a xogo todo aquelo? Porque os nosos pais non nos falarían así? [...]

Erguémonos calados e saímos sen falar. Fora, as rapazas baralleiras preguntan o qué nos dixo Don Antonio. Ninguén responde. Xa lles falará a elas (Filgueira Valverde 1929: 205).

A única posibilidade de salvación para as rapazas está en se comportaren de acordo co que agardan os homes das súas familias ${ }^{11}$, por tanto, seguindo un esquema que non permite tomaren elas as súas propias decisións. Defínense, xa que logo, en canto que irmás dos desleigados ou irmás dos bos e xenerosos, tal e como vemos no "mitin" final con que remata a obra:

Mira rapás: tí erel-o señorito da vila, nonsí?, xogador de tennis, bailarín de shotis, fillo de un señor de moito porqué, irmán de unhas rapazas á moda, que non saben facer o caldo -non, non te arrufes, que é certo- veraneante, socio da aburrida vagancia da mocedá das vilas; mais ten a nosa Terra unha caste de mozos, xente aldeán, xogadores de chave, bailadores de muiñeira, fillos de labradores ou de mariñeiros, irmáns de rapazas que saen ao fío da media noite a tornal-os regos, unha caste leial ao seu sangue... (Acuña 1936: 91-92).

9 Pénsese na realizada por García Barros (1930: 1-8) no Certame literario do "Día de Galicia e da Fala Galega" celebrado en Pontevedra en 1929 sob o tema: "Una vez limpio y fijo nuestro idioma, ¿qué resortes podrán emplearse para que lo adopten nuestras mujeres de la clase media y elevada a fin de verlo entronizado en todo los ámbitos de la Raza?".

${ }^{10}$ Sobre a consideración das mulleres en Lousada Diéguez (claramente herdada por Filgueira), véxase Rios Bergantinhos (2001: 94-98).

${ }^{11}$ Pais, esposos, noivos, irmáns... Lémbrese a este respecto a peza de Rodríguez Díaz (1935) De volta pr'a terra, onde a arxentina Teresiña se sente galega e mesmo pode falar o noso idioma por amor ao seu mozo, Andrés, galeguista convencido, mentres que a renegada e "solteirona" Quica volve convertida en "americana" sen posibilidades de se reintegrar no seu propio país. 


\section{O noso primeiro achegamento á obra: aparato titular, autor, prologuista e elementos paratextuais non verbais}

O carácter pedagóxico e exemplarizante do texto está fortemente marcado nos paratextos iniciais: a aparición da profesión asociada ao pseudónimo habitual do polígrafo pontevedrés, "J. Acuña, escolante"; a indicación de que a peza se insire no "Teatro Escolar Galego"12; no título, en principio un claro referente rural, mesmo con connotacións simbólicas da fusión das clases populares fundamentais do país (labregos e mariñeiros), a través da asociación ao espazo onde desenvolven as súas actividades. Porén, a partir do significado orixinario de "botar os gromos as plantas", acaba por se aplicar figuradamente á aparición progresiva de algo que está oculto ou que era descoñecido. Xustamente referíndose a este termo rematan as "verbas limiares", indicándose que aqueles que quixeren converterse en homes poden comezar a "vivir a nova vida que está xa a agromar", palabras repetidas por Nito ao final do lance segundo, cando, igual que Solovio, sente o seu ser renovado (Acuña 1936: 73). Coa mesma acepción aparece ao final das indicacións para a representación, neste caso salientando a idea de colectividade, de grupo: "'Agromar' é un berro de irmandade!". Da confrontación vila / aldea, perfectamente visíbel na estampa que ilustra o texto (cunha caracterización marcada pola utilización do moderno e deportivo pantalón curto dos "pitos da vila" e a pucha dos "rapaces da aldea"), ten de nacer a síntese que recolle o título e que xa marca a liña do elemento que debe prevalecer. O tema das diferenzas entre "nenos pobres" e "nenos ricos" xa fora tratado por Filgueira na serie de relatos curtos publicados con anterioridade (Filgueira Valverde 1925e). O nome escollido para identificar a peza, alén de poder ser un "calco semántico sobre o castelán brotar" (Monteagudo 1991: 301), simboliza a aposta por consolidar un modelo de galego culto a través dunha das vías máis traballadas por Otero Pedrayo ou Castelao: a ampliación semántica a partir de acepcións metafóricas ou abstractas que posibiliten o emprego para a expresión de novos conceptos das palabras patrimoniais.

O subtítulo (Farsa pra rapaces) ten unha función enfatizadora da tipoloxía textual en que o autor desexa inscribir a obra. Mais introduce tamén un elemento caracterizador da lingua co emprego de pra, forma que podemos considerar canónica naquela altura, que se opón no texto a para no enunciado "para perguntar por Nito" (Acuña 1936: 31), ao apareceren as dúas formas ao comezo do cadro segundo entre aspas, simbolizando seren estas palabras pronunciadas polos amigos do señorito que o veñen visitar, nunha primeira escena que se desenvolverá nese español agalegado característico dos "pitos da vila".

\footnotetext{
12 Idea reiterada no prólogo, cando Filgueira di que "Acuña viñera chantar un novo esteo no camiño apenas encetado do noso teatro, o primeiro esteo do teatro das nosas escolas" (Filgueira Valverde 1936a: 9)
} 
E, xa para rematar, a obra apreséntase cun autor descoñecido (J. Acuña) que precisa alguén de renome (Filgueira Valverde) para lle dar a benvida literaria. Sen esa presenza a publicidade da peza ficaría reducida a aqueles interesados no teatro galego, posibilitando o seu aval un prestixio conformado, individualmente, pola súa xa importante traxectoria investigadora, e, colectivamente, pola pertenza ao Seminario de Estudos Galegos e ao galeguismo organizado. A partir de aquí, as expectativas do público lector non decaerán, pois o prólogo que antecede a obra vai pór en riba da mesa as relacións entre autor e prologuista ofrecendo dados de interese desde o punto de vista literario, lingüístico e histórico, que pasamos a analizar.

\section{As "Verbas limiares"}

Tamén o prefacio e o epílogo cumpren unha función ideolóxica chave para entendermos a obra: o primeiro ao estabelecer unha loita entre dúas tendencias que puxan por se manifestar na mesma persoa, resultando gañadora aquela que se compromete coa causa galeguista, coa súa terra e co seu idioma; o segundo cobra unha forza inusitada mercé ao carácter sintético e a súa autonomía (xa salientada na apresentación inicial), quizais máis suxestivo canto que menos explícito, e, con maiores posibilidades teatrais polo seu ton marcadamente humorístico.

Nun interesante xogo ideolóxico-literario, Filgueira comeza por realizar unha aclaración que resulta absolutamente certa no que respecta ao libro a que nos estamos a referir ("Fixera mentes de lle non pór limiar a mais libros que aos meus"), pois se ben autor e prologuista non coinciden formalmente, non teñen, como acabamos de ver, o mesmo nome e apelido, e desa maneira se apresentan ao público lector desta farsa, Acuña e Filgueira son, en realidade, unha mesma persoa, e o prefaciador non fai máis que cumprir o que se impuxo: non prologar un libro que non fose seu. Nesta apresentación dunha dupla personalidade, dun autor desdobrado en dous que coinciden, ofrecénsenos dados biográficos do propio Filgueira ${ }^{13}$ (alumno de Lousada Diéguez, asistencia á primeira conferencia en galego en Pontevedra ofrecida por Otero, cursa estudos de Letras e Dereito en Compostela -“Acuña estudaba Dereito, eu adicábame mellor a Letras"-, participa no Seminario de Estudos Galegos), que realiza un percorrido pola súa infancia e mocidade e comenta que Acuña e o prologuista acaban por colaborar en diferentes xornais con distintas seccións, mesmo coa utilización de distintos idiomas cada un: “el en castelán, eu en galego".

${ }^{13}$ Dados que coinciden cos apuntados por Isla Couto (1932: 215) na súa participación na obra colectiva de Ultreya, Primeira Xeira. Misión biolóxica de Galiza, onde anota a importancia de Otero e de Losada Diéguez na vida de Filgueira e indica que A fiestra valdeira é unha das súas obras favoritas. 
Dúas cuestións merecen o noso interese de maneira principal:

- A primeira é o feito do recurso ao pseudónimo tan habitual e tan importante nunha literatura que está no inicio do seu desenvolvemento e conformación. Así, alén do gosto persoal pola utilización de pseudónimos en todas as épocas, esa tendencia pode verse favorecida pola necesidade de seren máis homes e mulleres ${ }^{14}$, de existiren máis escritores e máis compañeiros na causa. En literaturas pequenas, de resistencia, a creación de pseudónimos pode converterse en máis unha maneira de aparentar ser máis dos que realmente están para dar unha impresión de forza, de pluralidade e heteroxeneidade moitas veces inexistente. Esa é xustamente a nosa interpretación respecto da utilización do pseudónimo J. Acuña por parte de Filgueira en Agromar, e non o intento de "distanciarse dunha obra menor" ou de lle render

unha homenaxe a ese amigo imaxinario que todos, cando nenos, temos, a ese amigo que nos acompaña na infancia, co que mantemos interminables conversas "no colo da i-ama" -cando había amas-, "nos brinquedos de neno ou nos xogos de rapás" (Álvarez Ruiz de Ojeda 1992: 84).

Cando Nito lembra a súa infancia, non o fai acudindo á nostalxia dos xogos e a felicidade da nenez, senón para recuperar a lingua perdida naqueles beizos da súa ama e a profundidade das súas reflexións, opostas á conversa baleira dos señoritos. Trátase de renacer acudindo ás orixes, o que fai posíbel o seu reencontro coa Terra:

Nito: A miña i-ama, a que me adeprendeu o galego -e ben que lle ten berrado o meu pai - denantes do trafego de me arroupar no leito, decíame sempre: "Estás como un rei nunha cesta", "meu señorito pequeno". E agora ao agarimarme acochadiño dime que "estou como acio nun gueipo" e chámame "meu brañego", "meu espelliño mellor"...

Xelo: É un falar.

Nito: Si, é un falar. Pero eu non son o mesmo. Aborrezo o que denantes me gorentaba.

Xelo: Os ovos moles, as tartas, galiña...

Nito: Non, as cousas do señorío.

Xelo: Esas son cousas do señorío.

Nito: Bah. As outras: a conversa báfua, o facer que se fai, i-ese orgulo, Xelo, esa fachenda de ser máis, de ter máis, que non sei de que ven (Acuña 1936: 51).

\footnotetext{
${ }^{14}$ Sobre a tendencia dos escritores galegos a se mascararen sob pseudónimos femininos, véxase Álvarez Ruíz de Ojeda (1992: 69-92).
} 
Para a importante produción literaria desenvolvida na época eran poucas as persoas que estaban en condicións de atender as exixencias dun idioma que se quere levar a todos os ámbitos, sobre todo se estamos a falar de temas que requiran unha preparación específica, unha determinada instrución. Nesta perspectiva, o desdobramento faise necesario. Só así se pode explicar a participación de Filgueira nunha revista como Logos, intervindo nalgúns números con tres artigos diferentes, mesmo un a continuación doutro ${ }^{15}$ ou, en ocasións, de asinar coas iniciais do seu pseudónimo $J$. A. e falar de Filgueira tal e como sucede nos números 42 e 43.

- O recoñecemento de Filgueira como escritor bilingüe nesta etapa é unha obviedade. Dependendo de para que medio de comunicación, do tema, do momento, as súas intervencións van ser unhas veces en galego e outras en español, sen se axustar a ningunha regra de contido ideolóxico. Así, un dos seus primeiros artigos, con só 18 anos, dedica o seu traballo "A mi maestro el benemérito presidente de la Sociedad Arqueológica de Pontevedra don Castor Sampedro", e asina como

José Filgueira Valverde, alumno de las Facultades de Letras y Derecho en la Universidad Compostelana. Socio Numerario del Seminario de Estudos Galegos (Filgueira Valverde 1924b).

Poderiamos escoller outros exemplos, algúns deles anteriores (véxase Filgueira Valverde 1924a), en que pasaría o mesmo. O xogo proposto por Filgueira valería para opor as "Glosas" asinadas por "Juan de Acuña" no xornal El Ideal Gallego (por exemplo o 8 de Febreiro de 1925, titulada "La tuna", ou as varias de temática franciscana publicadas ese mesmo ano -Filgueira Valverde 1925b, 1925c e 1925d) aos "Vieiros" de Filgueira publicados en Logos, mais tanto un como o outro (se se nos permitir a reiteración no xogo), utilizaron as dúas linguas. Por iso o aceno ao lector feito por Filgueira ao final desta duplicidade (a conversión de Acuña ao galeguismo), non oculta a forte conflitividade vivida ao respecto, embora o escritor pontevedrés defendese a utilización do idioma galego e que unha das súas maiores preocupacións fose a non galeguización da Igrexa e a non confesionalidade relixiosa dos galeguistas:

Encol da mesa están dous xornás que o correo trouxo xuntos: un xornal de emigrados, un boletín católico. O xornal dos emigrados aldraxa en galego aos sacerdotes da miña terra por alleeiros, o boletín católico apoupa en castelán aos galeguistas por coincidir co programa dos masóns. Debrúzome na fiestra, perto do meu casal hai duas escolas, unha ceibe, dos católicos, outra do Estado, con mes-

\footnotetext{
15 Véxase o número 34 da citada revista, onde tras un artigo titulado "Na Festa de Christo Rei do ano xubilar", asinado como J. Acuña, Filgueira escribe outro artigo "Henri Bremond (1865-1933)", neste caso asinado como "FILGUEIRA VALVERDE". Para completar o número, J. A. volverá asinar a "BIBLIOGRAFÍA", sección que Filgueira cubriu en moitos dos números da revista, coas iniciais do pseudónimo de Juan Acuña.
} 
tres da ATEO. Na escola do Estado os rapaces acaban de cantar o hino galego e con seguranza neste intre estarán leendo uns poemas de Cabanillas, na escola católica as maestras bérranlles aos rapaces cando falan en galego. Eu penso que cicais nesta mesma hora se estén dando algúns mitíns por isas aldeias adiante; os oradores anticatólicos falarán con seguranza o galego; os dereitistas atacarán as variedades dos pobos co ensoño de unha centralización que ten moito mais que ver co humanismo e ca Revolución Francesa que ca idea pluralista do Estado Cristiano tradicioal (F[ilgueira] V[alverde] 1936b: 52).

Non está de máis ver as similitudes dos termos empregados: "Alleeiro" (Filgueira Valverde 1936a: 8), "Separatista" (Filgueira Valverde 1936a: 9) son os alcumes que se dedican os dous amigos nunha loita sen ciúmes, pois logo ían xuntos cobrar o seu traballo xornalístico.

A brincadeira chega mesmo ao extremo de situar a obra prologada a penas como un xogo pobre de técnica, sen comparación posíbel con outras, feitas e cheas, como a "Fiestra Valdeira", co comentario seguinte de Filgueira: "sei que Acuña non levará a mal esta sinceiridade". Rómpese aquí, máis unha vez, a obrigada laudatio da obra e autor por parte dun suposto prologuista alógrafo que interpreta o papel que corresponde ao prólogo de autor: escusar a obra na modestia e nunha necesidade circunstancial, a de pasar o tempo ou de contribuír á causa cun pequeno gran de area. Esta idea de abrir camiños que outros deben continuar enfronta os dous eus filgueirianos:

Quixen convencer a Acuña de que o editase, quixen que traballase en novos "xogos", uns de senso social a maña diste, outros de senso lírico, como as xeiras de Zorro ou de Meogo. Non quixo, i-adios: El non era poeta, nin tan xiquer literato, fixera "Agromar" nun lecer, pra abrir unha laboría onde outros viñesen traxeitar, "Eu labro, díxome; que sementen outros" (Filgueira Valverde 1936a: 10).

Outra idea importante é a de ter pretendido realizar un prólogo afastado das súas características habituais, sen se deixar levar polos tópicos, pois Filgueira declara non ser amigo destes textos iniciais, sobre todo se estes son alógrafos ${ }^{16}$. Neste sentido, denúncianse os prólogos alleos, entendidos como mercadoría, como "contratos" entre vellos e novos, como un xeito de submisión:

As avesas, o prólogo alleo é unha avinza curial. O escritor novo merca unhas verbas alaudosas do escritor vello a troques de lle poñer o nome na portada. O vello escribe enfastiado, coutando de non luxal-a sua sona con gabanzas de mais; o novo fai imprentar aquelas liñas serodias en letra grande, temendo que teñan leitores de menos. Unha contrata onde xogan choio e facenda, de costas ao arte [...].

I-en forza de gabar a Acuña sin me baixar a falar dél e da sua obriña, debullaría eiquí unhas verbas valeiras... (Filgueira Valverde 1936a: 7-8).

\footnotetext{
${ }^{16}$ Idea tamén compartida por Otero que sente os prólogos alógrafos como ruído innecesario, mesmo dis-
} torsionador da mensaxe que se quere transmitir. 
O xogo é, como se pode ver, perfecto. E dentro desta constatación de estarmos asistindo realmente a un relato autobiográfico do propio Filgueira ${ }^{17}$, nada impide que interpretemos literalmente as súas declaracións sobre a data da realización da peza e os intentos para ser estreada. Neste sentido, Filgueira cóntanos que a obra xurdiu no verán de 1932, meses despois de ter asistido á Misión Biolóxica cos Ultreya ${ }^{18}$, momento probábel en que xorde nel "a vocación pedagóxica, a arrincarme do isolamento de "Arquiveiro-Bibliotecario-Arqueólogo" (Filgueira Valverde 1936a: 10). A relación de Filgueira co teatro non foi esporádica nin referida tan só a do teórico que realizou diferentes traballos sobre a dramaturxia galega ${ }^{19}$, senón que, alén dos seus contributos teatrais (Filgueira Valverde 1969: 325-340), participou no grupo "Universidad" formado por Cotarelo:

Eu facía o modesto rol de traspunte e gardo algún dos libretos coas acotacións (Filgueira Valverde 1984: 63).

É posíbel, pois, que a obra fose ensaiada coa intención de ser levada á escena nestas datas, xustamente aproveitando a relación estabelecida cos rapaces do grupo, de quen mesmo se conta a situación en que se encontran uns anos despois. Todo, por tanto, moi lonxe da posición "distante e motivada por un afán esteticista e intelectual” (Riobó 2000: 28), algo que se non pode aplicar a Agromar. Mais a guerra civil española frustrou as posibilidades de observarmos a recepción deste e outros textos sen tempo para seren divulgados tras o horror franquista (Tato Fontaína 1999: 153-154).

\section{Primeiro e Segundo Lance}

A contraposición no primeiro lance estabelécese en dous diálogos mantidos, primeiramente polos "rillotes" da aldea, e despois polos "pitos da vila", en galego e español respectivamente, co mesmo tema de conversa e cunha visión totalmente enfrontada e irreconciliábel. O único elemento disonante con esta situación será a figura do médico, "D. Enrique", de quen se di o seguinte: "Guillose en Santiago. Es de esos que les da por el gallego". O lance remata co ofrecemento de doar sangue para o señorito accidentado realizado por un dos mozos da aldea, Xelo. Aínda que a intencionalidade sexa en principio gañar unha aposta para recuperar o seu can

${ }^{17}$ Que, como el diría de Otero "sempre soupo representar o seu propio papel, e non outro" (Filgueira Valverde 1979: 396).

${ }^{18}$ Que, segundo coñecemos, levaron a escena diferentes pezas teatrais, entre elas algunha de Cotarelo Valledor, tal e como Illa Couto ten referido a Uxío-Breogán Diéguez Cequiel, investigador que está a traballar sobre Álvaro das Casas e os Ultreya (véxase Diéguez Cequiel 2002: 93-105).

19 Entre os que cómpre lembrar o recollido nas súas Leccións de Literatura Galega, ou, cincuenta anos máis tarde, o traballo sobre o teatro de Cotarelo Valledor (Filgueira Valverde 1984: 59-812). 
Tulé, roubado primeiro polos señores e logo por un amigo do propio Xelo, axiña se ha descubrir que en realidade o rapaz tiña má conciencia por lle ter desexado algún mal a Nito ao telo privado da compañía do animal.

No segundo lance dásenos conta do proceso sofrido por Nito tras recibir o sangue de Xelo, imbuído dun espírito aldeán que xa latexaba nel, pois agora lembra o galego con que se dirixía a el a súa ama de pequeno, a pesar da oposición de seu pai. A dignificación dos maiores lígase a este proceso de conversión espiritual, onde Nito acabará por falar "o saber dos vellos por boca dos rapaces". De feito, na primeira escena, falan o accidentado convalecente e o seu salvador, Xelo, quen, alén de o instruír nos saberes labregos, acaba por se recoñecer como un vello, apreixando a esencia das cousas, algo que Nito sente moi afastado das súas habituais preocupacións:

Nito: Dis unhas cousas...! Como a miña i-ama. Como Don Enrique... Cousas fondas, que eu non enxergo e que tí mesmo non sabes a fondura que teñen. Quén chas adeprendeu?

Xelo: Son falares de vellos. Ás veces fala ún con verbas que escoitou de pequeno. Agora a falar dos enxertos e das mazáns, tiña mesmo diante, falando, ao meu abó (Acuña 1936: 52).

A confrontación e a ruptura cos seus amigos vilegos non se fai agardar, mais el mantense e defende con dignidade a súa escolla lingüística. O seu discurso fortemente ideoloxizado provoca as iras dos seus amigos, incapaces de comprenderen o seu cambio de idioma. Entre os insultos que lle dedican ao se despediren está o de "Marcos da Portela", feito que evidencia a tradición reivindicativa en que se insire tras a súa conversión. En realidade, este, e outros referentes literarios introducidos no texto (mesmo con citas de poemas en galego e catalán), conforman un lector ideal que, sen ser o modelo culto oteriano, si que ten que pertencer a unha tradición galeguista e sentirse predisposto a compartir unha determinada concepción do mundo dominada polo achegamento á aldea para obter unha comprensión global do contido da peza. Tamén é nesta liña como temos que interpetar a decisión de Nito, tras as convincentes palabras de D. Enrique, de estudar como unha exixencia da súa Terra, utilizada para incluír un dos posicionamentos habituais da época, a necesidade de eliminar a referencia castelá, procurando a cultura alén das fronteiras do estado español:

Nito: Pero terei que ir a Madrid. Con Lolo, con Perico, con todol-os miñocas.

Don Enrique: Non, a Madrid non. Mais lonxe. Que saben en Madrid das nosas cousas? A Dinamarca, a Bélxica, ás terras ceibes en que non hai señoritos nin mendiños, onde se vive pra o traballo e pra o ben (Acuña 1936: 74-75). 


\section{Remate}

A conversión ao galeguismo modifica totalmente a "Nito", que se apresenta "vestido ao xeito dos cativos da aldeia", cun "legón ao lombo" e cantando a primeira estrofa do poema de Cabanillas "Galicia”. Á súa beira vai aparecer un rapaz da vila de veraneo con "pantalón branco, camisa sport, raqueta ao brazo, andar aseñoritado", quen cantará calquera "parbada á moda. Por enxempro: 'Pichi, es el chulo que castiga...".

O enfrontamento colectivo anterior faise agora individual. Un renovado Nito, xa convertido en Xanciño, conversa co señorito da Coruña que pasa as vacacións aburrido na aldea. A ridiculización do español empregado ("Te soy de La Coruña", -Acuña 1936: 81; "Bah, mi padre está muy ocupado. Y también te va por allí a las veces", -Acuña 1936: 82; "Soy aún muy nuevo y no quiero saber de eso", -Acuña 1936: 86), adubíase coas referencias ao inglés e a burla despiadada de Xan, que lle segue a corrente para desmontar cada unha das súas opinións frívolas sobre o mundo, deixando en evidencia a súa hipocrisía e fachenda.

Ao final, reaparece novamente a voz de Don Enrique explicando o papel do señorito Juanito tras ouvir a chamada da Terra, confirmando esa visión de redención da Galiza a través da fusión da fidalguía co pobo, nun equilibrio ideal que compense os diferentes saberes de cada clase:

E deixando a conversa vagaceira, i-o vivir levián, douse en saír pol-a campía, a falar cos probes, a adeprender os ditos dos vellos, a traballar nas leiras, a beber cos ollos a fondura infinda da paisaxe nos mais outos curutos. Pra ser mañán, como hoxe son eu, consello e guía dos que sabendo máis que nós en tantas cousas... precisan do saber novo que nós podemos ter, sendo, ao mandado dos irmáns labregos, un paisano con estudios, xornaleiro dos paisanos que non os teñen (Acuña 1936: 92).

O remate significa o cerramento do círculo, pois volve levarnos ao comezo, nunha proposta totalmente afastada dun refuxio estético noutros tempos; nada máis próximo ao desexo compartido con Otero de crear minorías dirixentes que representen as arelas do pobo e que volvan ás aldeas na procura da súa rexeneración ${ }^{20}$.

\section{A lingua e a súa consideración}

Xa por último, cómpre referírmonos á fala, á aposta polo galego popular que, segundo opina Filgueira, está a ser maltratado, refugado polos escritores. Esta idea, xa expresada no prólogo ${ }^{21}$, terá continuación no desenvolvemento da peza, intentando loitar contra os prexuízos das mulleres das clases medias e do señoritos:

\footnotetext{
20 Véxase a este respecto Quintana / Valcárcel (1988: 67-74).

21 "Mais a obra gorentoume pol-o seu acento oral, popular, tan refugado por todos nós" (Filgueira Valverde 1936a: 9).
} 
Unhas señoritiñas cursis abanean o "María de la O” pra lembrármonos que saímos da nosa terra. "Puah, Galicia, que asquito...". Rube no auto un rapazote que vai pasal-o domingo na "capital". Dinos nun patois chulesco cousas inanes dos votos, do baile e da timba. A volta escoitaremos "Rosío" e virá axustarse na dianteira unha señora foupella, vestida de laberca, a malsinar das mulleres da aldeia que falan como cadelas e teñen porcos os míseros fogares (Filgueira Valverde 1936a: 11).

Cómpre lembrarmos que non só en 1936 existía xa unha importante tradición escrita que ía conformando unha determinada lingua literaria, senón que se deran algúns pasos para a súa estandarización, movementos a que Filgueira Valverde non fora alleo. De feito, a súa participación en diversas obras gramaticais e na proposta de estabelecemento dunhas normas elaboradas polo Seminario de Estudos Galegos fai que desde Logos se asuman esas normas como as orientacións básicas da escrita do idioma. Sen entrarmos agora nesta polémica, vexamos as palabras do proprio Filgueira (utilizando o pseudónimo de J. Acuña), a este respecto:

A Sección de Filoloxía do Seminario de Estudos Galegos que dirixe o sabido mestre compostelán e colaborador desta nosa revista, Pauliños Pedret Casado, unha das figuras mais esgrevias do crero galego nos nosos días, ven traballando dende a sua fundación no estudo da unificación da língua galega, vello anceio dos escritores da nosa fala e dos leitores todos da terra galega que nas variedades que superan a nosa riqueza dialectal topan algunha dificultade pra cultivaren o belido idioma dos Cancioeiros.

Froito de detidas investigacións, estas normas, exempro de prudencia e de siso, non unifican mais que o puramente necesario, deixando un marxen de variedades que o tempo mesmo se encargará de reducir a unidade co cultivo literario, por sorte cada vez mais espallado da nosa lingua. Do mesmo xeito nas espiñentas eleccións entre as formas lusitáns e as casteláns foron de cote imparcialmente escollidas aquelas que respondían á necesidade do uso actual ou a unha superioridade técnica sin grandes e perigosas innovacións (A[cuña] 1933c: 192).

A obra, en xeral cun galego moi coidado, apresenta algunha incorrección na colocación pronominal, no emprego de te e che ou na aparición dun tempo composto ("Nito: Bah. Si o houbera feito antes", -Acuña 1936: 58), erros nalgún caso xustificados probabelmente por ser o señorito quen, agora convertido ao galeguismo, fala un galego á forza diferente do utilizado polo resto das personaxes populares da obra. Notemos algúns destes enunciados problemáticos, por exemplo, cando Nito fala por primeira vez galego diante dos seus amigos e cando conversa cos rapaces da aldea:

— Qué? Non entendedes ou vos fai gracia? (Acuña 1936: 55).

— O ves, Xelo (Acuña 1936: 69). 
Ora ben, non sempre estes descoidos gramaticais poden ser atribuíbeis ao desexo de mostrar a lingua dun neofalante, mesmo co galego como lingua do seu contorno desde a infancia, aparecendo en ocasións algún que outro erro na lingua dos galego-falantes iniciais:

— “Xelo: N'os vin. Saín hoxe, ao pomar, por primeira ves. Don Enrique dixera de non te deixar soio, a escismar, que te contara contos dos vellos e xogos dos nenos" (Acuña 1936: 61).

Canto á representación de certos fenómenos fonéticos de carácter dialectal, cómpre salientarmos o emprego do seseo final en determinadas voces, como rapás ${ }^{22}$ (Filgueira Valverde 1936a: 8; Acuña 1936: 24, 78, 79 e 91), vos (Filgueira Valverde 1936a: 8), ves (Acuña 1936: 23 e 61) e lus (Acuña 1936: 39). Igualmente, é destacábel a influencia da hipercorrección da gheada en Guan (Acuña 1936: 64).

Graficamente, ademais de opcións sistemáticas como o emprego de $a o(s)$ e a eliminación de acentos graves e circunflexos, é constatábel unha importante redución no uso de apóstrofos e trazos, signos moi utilizados na etapa enxebrista ou diferencialista, segundo a terminoloxía empregada por Fernández Salgado e Monteagudo Romero (1995: 99-176), achegándose o galego considerabelmente ao modelo lingüístico actual. Canto aos trazos, estes resérvanse:

- para a unión do verbo co artigo, fenómeno que non se realiza de maneira sistemática e que sempre prioriza a marcaxe de $o$, $a$, os, as como formas do artigo: milloral-a obra (Filgueira Valverde 1936a: 10), todol-os seus temas (Filgueira Valverde 1936a: 10).

- no encontro da conxunción copulativa $i$ coa vogal con que comeza a palabra seguinte: $i$-eu (Filgueira Valverde 1936a: 9), pol-a i-alma, i-enfíalle (Acuña 1936: 21).

O uso do apóstrofo nalgunhas ocasións contrasta coa tendencia á súa eliminación, sobre todo na contracción da preposición de co pronome persoal de terceira persoa ou cos demostrativos (d'ela, d'aquela -Acuña 1936: 25 / diste -Filgueira Valverde 1936a: 10), e esporadicamente coa aglutinación da preposición en e algúns pronomes (n’unha -Acuña 1936: 31). Probabelmente foi esa procura dunha linguaxe popular a que motivou a aparición tamén do apóstrofo en dúas ocasións sinalando a contracción producida na fala entre o adverbio de negación e unha forma do verbo ser: "N'é mester" (Acuña 1936: 22), "n’o fai" (Acuña 1936: 30) "Fago o que ti n'és home de faguer” (Acuña 1936: 29).

\footnotetext{
22 A única excepción en que lemos rapaz (Acuña 1936: 71), esta forma aparece en boca de D. Enrique, caso que, de ser intencionado (feito dubidoso, pois máis adiante D. Enrique emprega o mesmo vocábulo con seseo final), podería querer indicar os diferentes rexistos existentes no interior do galego. De feito, a lingua de D. Enrique non é a de Xelo, e non só polos diferentes contidos que un e outro desenvolven.
} 
Desde o punto de vista morfolóxico, a regularidade, sen ser total, é a regra xeral:

- O resultado de -ANU / -ANA é an: citra levián (Filgueira Valverde 1936a: 8), man, chan (Filgueira Valverde 1936a: 11), irmán, vran (Filgueira Valverde 1936a: 12), levián vivir (Filgueira Valverde 1936a: 13), a miña irmán (Acuña 1936: 25), cristián (Acuña 1936: 26), mazáns (Acuña 1936: 49, 50, 52, 66), mañán (Acuña 1936: 68, 70 e 92), camiño aldeán (Acuña 1936: 79), xente aldeán (Acuña 1936: 92). Achamos un único caso de ruptura da norma na forma pedra grá (Filgueira Valverde 1936a: 11).

- O plural das palabras rematadas en -n é -ns: vacacións (Filgueira Valverde 1936a: 10), mazáns (Acuña 1936: 50, 52 e 66), estrobáns (Acuña 1936: 59), mans (Acuña 1936: 62), irmáns (Acuña 1936: 92).

- O plural das palabras polisílabas rematadas en $-l$ apresenta a solución central: xornás (Filgueira Valverde 1936a: 8), casás (Filgueira Valverde 1936a: 11), papés (Filgueira Valverde 1936a: 12) e milleirás (Acuña 1936: 75). A excepción, cun plural en -les achámola en caracoles (Acuña 1936: 83).

Temos de salientar como fenómenos particulares:

a) A aposta polo emprego do infinitivo flexionado: "Terán aínda un leme de fervor por serviren aos seus?" (Filgueira Valverde 1936a: 11); "Unhas señoritiñas cursis abanean o "María de la O" pra lembrármonos que saímos da nosa terra" (Filgueira Valverde 1936a: 11); "E traballar nos agros e saírmos ao mar, e rubir aos curutos mais outos" (Filgueira Valverde 1936a: 12); "sin iren a ningures" (Acuña 1936: 22); "Nito, ao sairen os rapaces, debruzouse a chorar caladamentes" (Acuña 1936: 71).

Nalgunha ocasión, porén, esta potenciación provoca un uso errado pola falta de concordancia co seu suxeito: "eu a rematar Letras en Zaragoza, pra seren Arquiveiro de calquer Concello poirento ou Arqueólogo de un museo non nado" (Filgueira Valverde 1936a: 9).

b) A utilización da interpolación: "que Dios me non poña diante" (Acuña 1936: 21); "cando me eu teña afeito á vosa vida" (Acuña 1936: 70).

Este recurso pode ser empregado incorrectamente, algo habitual nos textos de comezos de século (Sánchez Rei 1999: 189), dando lugar a enunciados agramaticais: "Me non trabou de milagre" (Acuña 1936: 27).

As concesións a fenómenos dialectais, están na representación xa citada do seseo final, a utilización do verbo faguer (Acuña 1936: 60) e do adverbio eiquí (Acuña 1936: 38 e 68), cuxo uso foi claramente potenciado polo afán diferencialista. Mais a característica habitual deste período, o enxebrismo entendido como un abuso 
deste fenómeno que dificulta considerabelmente a lectura, ten unha presenza menor da agardada neste texto, restrinxíndose a formas habituais e case consagradas na época. E iso aínda que Filgueira participe nese chamamento á recuperación do elemento enxebre, entendido como fuxida e defensa do español, procurando o refuxio no léxico rural e na literatura medieval, verdadeiras fontes lingüísticas:

Xustificar as moitas tachas do noso traballo seria darlle unha importanza que non ten. Ben coñecemos que está suxeito ás mais acedas críticas e á mais fonda revisión. Mais isto non amingoará a nosa ledicia ao termos posto as nosas cativas posibilidades ao servizo da grande Obra enxebrizante, chamando a ela novos e mais asisados laboureiros (Filgueira Valverde, X. / Tobio Fernandes, L. / Magariños Negreira, M. / Cordal Carus 1926).

Aínda así, alén da galeguización de claros españolismos léxicos (como carreteira -Acuña 1936: 55), existen algúns hiperenxebrismos: escadeiras (Filgueira Valverde 1936a: 8), sinceiridade (Filgueira Valverde 1936a: 10), hourizonte (Filgueira Valverde 1936a: 11) ou primaveira (Acuña 1936: 50). É tamén frecuente a vacilación entre solucións patrimoniais, eruditas e semieruditas para os cultismos, o que dá lugar a formas como enxempro (Filgueira Valverde 1936a: 9), crarexala (Acuña 1936: 14), espricas (Acuña 1936: 42), espricades (Acuña 1936: 63).

O criterio diferencialista, xunto coa fuxida consciente do castelanismo, é o que explica a reiteración de formas como anceios $^{23}$ (Filgueira Valverde 1936a: 8), arelas (Acuña 1936: 52) e degoiros (Acuña 1936: 52), a substitución de palabras, cabeza, subir e alto(s) por verbas (Acuña 1936: 40, 69, 73 e 89), testa (Filgueira Valverde 1936a: 11 / Acuña 1936: 68), rubir (Filgueira Valverde 1936a: 8 e 12) e outo(s) (Filgueira Valverde 1936a: 12 / Acuña 1936: 24 e 92) e a preferencia de formas derivadas de ollar (Acuña 1936: 53 e 71) e enxergar (Acuña 1936: 52) no canto de ver ou mirar. A escolla léxica evidencia a procura dun léxico tradicional, moitas veces aplicado a novos conceptos: avinza (Filgueira Valverde 1936a: 7 e 10), encetado (Filgueira Valverde 1936a: 9), merados (Filgueira Valverde 1936a: 10), xérmolo (Filgueira Valverde 1936a: 11), arredaría (Acuña 1936: 68), choutar (Acuña 1936: 75), inzado (Acuña 1936: 92). A opción elixida non obvia a aparición de neoloxismos, como sport (Acuña 1936: 79) e a introdución de formas recollidas do portugués (como após de -Filgueira Valverde 1936a: 11), plenamente galegas segundo a filosofía lingüística máis xeral na época:

Entraban asimismo en nuestros propósitos hacer una relación de palabras portuguesas que no nos parecían propias del idioma gallego, pero después de consultar concienzudamente nuestros escritos de diversa índole de los siglos XIII, XIV, XV

23 Para Santamarina (1995: 69), forma cunha grafía portuguesa por anseios, que mesmo remataría por dar un verbo anceiar inexistente en portugués. 
y XVI y de esculcar de modo minucioso en el lenguaje hablado en la actualidad, hemos convenido en el abandono de tal tarea por considerarla inútil e ilógica, puesto que llegamos al pleno convencimiento comprobable por quien quiera, de que no existe término netamente portugués que no sea gallego, y viceversa; cosa que conviene subrayar para que no la desconozca nadie (Irmandades da Fala 1933).

Son tamén abundantes os vulgarismos, sempre desde unha perspectiva actual, pois é evidente que algunhas destas solucións eran vistas no galego escrito da época como pertencentes á norma padrón: perfeución (Acuña 1936: 26), bunito (Acuña 1936: 28), bunitas (Acuña 1936: 82), frábica, arbres (Acuña 1936: 50), probe (Acuña 1963: 63), leutricidá24 (Acuña 1936: 87).

A esta descrición hai que sumar o emprego de arcaísmos: vegadas (Filgueira Valverde 1936a: 12), tíduo (Acuña 1936: 14) ou door (Acuña 1936: 40).

Canto aos castelanismos, as formas empregadas son aquelas frecuentes no galego popular, moitas veces cun forte valor expresivo: grado (Filgueira Valverde 1936a: 10), leer (Filgueira Valverde 1936a: 12), lee, créedesme (Filgueira Valverde 1936a: 14), caballero, pinal ${ }^{25}$ (Acuña 1936: 21), bueno (Acuña 1936: 24, 29, 41 e 71), Dios (Acuña 1936: 24, 43 e 62), verdá (Acuña 1936: 60), señardá (Acuña 1936: 67), andivese (Acuña 1936: 72), andivemos (Acuña 1936: 86), inxenieros (Acuña 1936: 74), mocedá (Acuña 1936: 92).

Especialmente relevante é o emprego dun español agalegado, dificilmente asumíbel como correcto, mais que contribúe ao retrato dexenerado e corrupto que se fai dunhas clases só preocupadas pola aparencia, os cartos e o lecer. Vexamos algún exemplo non só de galeguismos léxicos, senón tamén morfosintácticos ${ }^{26}$ : "El coche no carburaba bien. Y, a veces, me tiene fallado en la dirección" (Acuña 1936: 31); "Siempre a meterse donde no los llaman" (Acuña 1936: 32); "Y sois más nuevos" (Acuña 1936: 34); “A ver si te vas tú, mangallón, que ahora dá vergüenza ser amigo tuyo" (Acuña 1936: 35); "Que bruto! Por una apuesta. Una cosa así. No las cavilan!” (Acuña 1936: 44).

Atendéndomos ás actitudes e comportamentos, é evidente o desprezo e desconsideración que teñen os "pitos cairos" polo idioma, asegurando que "eso es cosa de

${ }^{24}$ É o xogo de Xanciño xa co seu ser renovado o que leva a formular este vulgarismo, probabelmente a deformación que agardaría o rapaz da cidade con quen dialoga finxindo non ter noticia das modernidades da urbe. Convértese así nunha demostración do dominio de diferentes variantes e nunha loita contra a ridiculización da fala popular.

${ }^{25}$ Mais D. Enrique ha falar máis adiante dos piñeiros (Acuña 1936: 74).

${ }^{26}$ Nótese, neste sentido, a frecuencia da aparición de perífrases verbais propias do galego e da introdución do infinitivo xerundial que, como xa vimos noutros exemplos, é utilizado tamén nos diálogos en galego. 
criados" (Acuña 1936: 55), que "Así vendrá luego el comunismo" e exixindo a Nito que fale "en cristiano" (Acuña 1936: 57). Igualmente, fica en evidencia a sorpresa da mudanza lingüística de Nito, que pasa agora a se identificar co grupo de rapaces da aldea, pois, ao falar coma eles, "Xa non somella o señorito Juan". O funcionamento do idioma como marca de clase social será aínda factor fundamental do encontro producido no remate entre un señorito coruñés e Nito, incapaz o primeiro de considerar a posibilidade de o segundo se estar expresando na lingua do pobo.

\section{Conclusións}

A interacción de dous códigos lingüísticos responde en todo o momento a unha intencionalidade exemplificadora de comportamentos e actitudes que se pretenden mudar, e, nese sentido, a mensaxe que se transmite é claramente rupturista da diglosia habitual na sociedade que se describe. $\mathrm{O}$ discurso da peza está dominado por unha alternancia de linguas e variedades perfectamente deseñada e dirixida polo seu autor, e non pode, por tanto, ser incluída sen máis, no caixón de obras bilingües ou diglósicas, ao se sustentar xustamente na idea de facer evidente esa situación para rematar con ela. A súa intención principal é contribuír a ese renacemento lingüístico que posibilitou que se percorrese o camiño ás orixes, para Filgueira, como para moitos, encarnados na tradición labrega, a única non alienada pola cultura dominante. Nas palabras que el e outros autore ${ }^{27}$ asumiran, chegaran novos tempos:

O idioma galego que chegóu, asoballado pol o castelán, a arrecantarse nas aldeias, fuxindo da burocracia alleeira das vilas, a vella fala dos Cancioeiros, que fora língoa poética no meioevo das terras occidentaes, veu a usarse en noxentas antroidadas e o pobo mesmo tivo a míngoa o empregal a. Mais en poucos anos de renacenza reconqueriu a sua sona literaria, escadou a poucos os boletís, entrou a furto nas conversas, acougou nos xuntoiros e con forte pulo leva camiño de superar, no presente rexurdimento, as antigas grolias (Filgueira Valverde, X. I Tobio Fernandes, L. / Magariños Negreira, M. / Cordal Carus 1926).

27 Como Antón Vilar Ponte, outro dos defensores da procura da esencia da galeguidade no mundo aldeán: "Hasta ahora, a través de nuestra larga decadencia, sólo los labriegos, los aldeanos fueron artistas gallegos dignos de tal nombre. Porque ellos cultivaron y conservaron las cántigas, los bailes, las tradiciones, el culto a la tierra, la riqueza del idioma; sólo ellos, con sus almas influídas por el paisaje, supieron subsumir el propio ser en la eterna armonía del pedazo de cosmos donde Dios le dio vida. Todos los elementos privativos del arte indígena quedaron perpetuados por ellos solamente en la pantalla del tiempo. Sin ellos, Galicia en el pórtico del futuro vería escrito el "lasciati ogni speranza", que Dante leyó en el liminar del Infierno. Los otros gallegos, los gallegos urbanos, los gallegos de partida bautismal únicamente, con toda su ciencia y su arte no han hecho cosa fecunda ni de la menor transcendencia" (Villar Ponte, A. 1925: X). 
Desde unha perspectiva lingüística, o modelo de galego de Agromar pertence ao que Carballo (1981b e 1988) ten denominado como fase supradialectal, situándose a cabalo entre a etapa enxebrista e a protoestándar sinalada por Fernández Salgado e Monteagudo Romero (1995). É evidente xa a esta altura en algúns autores, e entre eles nunha persoa vinculada á elaboración e reflexión sobre o corpus, a asunción das directrices emanadas das Normas pra a unificazón do idioma galego, feitas públicas polo Seminario de Estudos Galegos en 1933. Aínda que este e outros textos con intención prescritiva publicados nestes anos teñan sido considerado como propostas insuficientemente socializadas ${ }^{28}$, a transición ao modelo protoestándar está xa realizada nos últimos anos da década dos 30, cun modelo moito máis próximo ao de Castelao no Sempre en Galiza que ao de Otero Pedrayo, exemplo habitual de diferencialismo lingüístico. Así pois, a simplificación gráfica, a redución das posibilidades dialectais na morfoloxía, unha certa moderación no diferencialismo e a readaptación de palabras populares para seren utilizadas noutros contextos ofrecen un esquema que ten moito a ver coa vontade manifesta do nacionalismo anterior á guerra civil española por dotar o idioma de todos aqueles elementos que contribúan ao seu prestixio e dignificación, entre eles, o seu estudo gramatical e léxico e a conformación dun modelo estándar de lingua.

\section{Referencias bibliográficas}

A[cuña], J. (pseudónimo de Filgueira Falverde, J.) (1933a): “'Pepa Andrea’ Novela iñota de Pedro Guimarey esceificada por J. Pérez Parallé. Nós. Publicacións Galegas e imprenta. Santiago, 1933”, en Logos (X-1933) 34: 176.

A[cuña], J. (pseudónimo de Filgueira Falverde, J.) (1933b): "Na Festa de Christo Rei do Ano Xubilar", en Logos (X-1933) 34: 165-166.

A[cuña], J. (pseudónimo de Filgueira Falverde, J.) (1933c): “"Algunhas normas para a unificación do idioma galego'.-Seminario de Estudos Galegos. Santiago”, en Logos (XI-1933) 35: 192.

A[cuña], J. (pseudónimo de Filgueira Falverde, J.) (1934a): "Novas da nosa Galicia", en Logos 42: 87-88.

A[cuña], J. (pseudónimo de Filgueira Falverde, J.) (1934b): "Biliografía”, en Logos 43: 104.

Acuña, J. (pseudónimo de Filgueira Valverde, X.) (Escolante) (1936): Agromar. Farsa pra rapaces. Prólogo de Filgueira Valverde. Teatro Escolar Galego (Lugo: Editorial "Palacios").

\footnotetext{
28 Algo con que non concorda Fernández Salgado (2000: 316) ao afirmar que estas normas foron asumidas por dúas das publicacións máis relevantes do momento: Nós e A Nosa Terra.
} 
Álvarez Ruiz de Ojeda, V. (1992): "Os que se ocultan: a práctica do pseudónimo na literatura galega”, en Anuario de estudios literarios galegos: 69-92 (Vigo: Galaxia).

Beramendi, J. G. / Núñez Seixas, X. M. (1995): O Nacionalismo Galego (Vigo: A Nosa Terra).

Beramendi, J. G. (1999): "Unha imaxe ambivalente e cambiante: os galegos segundo os galeguistas (1840-1959)", en Kreemer, D. (ed.): Actas do V Congreso Internacional de Estudios Galegos: 3-21 (Trier: Ediciós do Castro / Publicacións do Centro de Documentación de Galicia da Universidade de Trier).

Bernárdez, C. L. / Ínsua, E. X. / Millán Otero, X. M. / Rei Romeu, M. / Tato Fontaíña, L. (2001): Literatura Galega. Século XX (Vigo: A Nosa Terra).

Cabo Villaverde, M. (1999): "O ruralismo na construcción do discurso político na Galicia da primeira metade do século XX", en Dieter Kremer (ed.): Actas do V Congreso Internacional de Estudios Galegos. Volume I: 289-299.

Carballo Calero, R. (1981a)[1963]: Historia da literatura galega contemporánea (Vigo: Galaxia).

Carvalho Calero, R (1981b): “A constituiçóm do galego como língua escrita" en Problemas de Língua Galega: 37-51 (Lisboa: Sá da Costa Editora).

Carballo Calero, R. (1988) [1972]: “A liña do galego literario”, Grial, 36: 129-137.

Diéguez Cequiel, U. (2002): “Álvaro das Casas e a súa actividade política na Galiza republicana (1931-1936)", en A Trabe de Ouro 49: 93-105.

Fernández Salgado, B. / Monteagudo Romero, H. (1995): "Do galego literario ó galego común. O proceso de estandardización na época contemporánea", en Monteagudo, H. (ed.): Estudios de sociolingüística galega. Sobre a norma do galego culto: 99-176 (Vigo: Galaxia).

Fernández Salgado, B. (2000): Os rudimentos da lingüística galega. Un estudio de textos lingüísticos galegos de principios do século XX (1913-1936). Anexo 47 de Verba (Santiago de Compostela: Universidade de Santiago de Compostela).

Filgueira Valverde, J. (1924a): "Galicia recibe al nuevo arzobispo", en El Ideal Gallego, 6-IV-1924.

Filgueira Valverde, J. (1924b): "De una ingenua liturgia. La Nao del Corpus en Pontevedra", en Galicia (Diario de Vigo) 582, 10-VIII-1924.

Filgueira Valverde, J. (1925a): "La tuna”, en El Ideal Gallego, 8-II-1925.

Filgueira Valverde, J. (1925b): "La estatua de San Francisco”, en El Ideal Gallego, 28VII-1925. 
Filgueira Valverde, J. (1925c): "San Francisco en Santiago", en El Ideal Gallego, 16IX-1925.

Filgueira Valverde, J. (1925d): “A Asís y Roma, ciudades 'meta de peregrinos"”, en El Ideal Gallego, 3-X-1925.

Filgueira Valverde, X. (1925e): Os nenos (Pontevedra).

Filgueira Valverde, X. / Tobio Fernandes, L. / Magariños Negreira, M. / Cordal Carus (1926): Vocabulario Popular Galego-Castelán (Vigo: Edición de El Pueblo Gallego).

Filgueira Valverde, X. (1929): “Unha lección de Lousada Diéguez”, en Nós 71: 204205.

Filgueira Valverde, X. (1933a): “Henri Bremond (1865-1933)”, en Logos 34: 167-168.

Filgueira Valverde, X. (1933b): "Leccións de Literatura Galega".

F[ilgueira] V[alverde, [X.] (1935): "Vieiros. Da táctica i-o apostolado", en Logos 47: 105-107.

Filgueira Valverde, X. (1936a): "Verbas limiares", en Acuña, J. (pseudónimo de Filgueira Valverde, X.) (Escolante) (1936): Agromar. Farsa pra rapaces. Prólogo de Filgueira Valverde: 7-13. Teatro Escolar Galego (Lugo: Editorial "Palacios").

F[ilgueira] V[alverde], X. (1936b): "Vieiros. A Eirexa i-as linguas vernáculas", en Logos 49: 51-54.

Filgueira Valverde, X. (1969): “Aucto de como Santa María foi levada aos ceos pra a festa da Nosa Señora de Agosto", en Grial 25: 325-340.

Filgueira Valverde, X. (1979): "Os seudónimos de Otero Pedrayo", en Filgueira Valverde, X.: Adral: 393-396 (Sada-A Coruña: O Castro).

Filgueira Valverde, X. (1984): Unha ollada ó teatro de Cotarelo", en Presencia de Armando Cotarelo en Galicia: 59-81 (Santiago de Compostela: Dirección Xeral de Cultura da Xunta de Galicia).

Freire Lestón, X. V. (1993): Lembranzas dun mundo esquecido. Muller, política e sociedade na Galicia contemporánea. 1900-1939 (Santiago de Compostela: Laiovento).

García Barros, M. (1930): "Falemos na nosa fala", en Día de Galicia de 1930: 1-8 (A Estrada: La Artística).

Guimarey, P. [pseudónimo de Pérez Parallé, J. Ma] (1933): Pepa Andrea. Novela iñota de... esceificada por J. Pérez Parallé (Santiago: Nós).

Irmandades da Fala (1933): Vocabulario castellano-gallego (La Coruña: Moret). 
Isla Couto, X. (1932): "[Diario]”, en "Ultreya. 1ª Xeira (Misión Biolóxica de Galiza)", Nós 107: 214-215.

Monteagudo, H. (1991): “A modernización do léxico galego en Sempre en Galiza e a norma léxica do galego culto actual”, en Brea, M. / Fernández Rei, F. (coords.): Homenaxe ó Profesor Constantino García. Volume I: 293-320 (Santiago de Compostela: Departamento de Filoloxía Galega da Universidade de Santiago de Compostela).

Moreno Villar, X. M. (1997): "O campo e a cidade na literatura e pensamento galegos", en Fernández Salgado, B. (ed.): Actas do IV Congreso Internacional de Estudios Galegos: 323-332 (Oxford: Centro de Estudios Galegos).

Nogueira, Ma X. (1997): "A utilización didáctica do corpus paratextual no estudio da literatura galega", en Marco, A. (ed.): Língua, literatura e arte. Aspectos didácticos. Actas do Seminário Interdisciplinar celebrado en Santiago do 24 ao 27 de abril de 1996: 261-273 (Santiago de Compostela: Departamento de Didáctica da Língua e a Literatura da Universidade de Santiago).

Quintana, X. R. / Valcárcel, M. (1988): Ramón Otero Pedrayo. Vida, obra e pensamento (Vigo: Ir Indo).

Rabunhal, H. (1994): Textos e contextos do teatro galego. 1671-1936 (Santiago de Compostela: Laoivento).

Riobó, P. P. (2000): O teatro galego contemporáneo (1936-1996) (A Coruña: Biblioteca-Arquivo Teatral Francisco Pillado Mayor / Departamento de Filoloxías francesa e galego-portuguesa da Universidade da Coruña).

Rios Bergantinhos, N. (2001): A mulher no nacionalismo galego (1900-1936). Ideologia e realidade (Santiago de Compostela: Laiovento).

Rodríguez Díaz, R. (1935): De volta pr'a terra. Comedia en dous cadros. $2^{a}$ parte de Cartas abertas. (Buenos Aires: s.i.).

Sánchez Rei, X. M. (1999): Se o vós por ben teverdes. A interpolación pronominal en galego (Santiago de Compostela: Laiovento).

Santamarina, A. (1995): "Norma e estándar" en Monteagudo, H. (ed.) Estudios de sociolingüística galega. Sobre a norma do galego culto: 53-98 (Vigo: Galaxia).

Seminario de Estudos Galegos (1933): Algunhas normas pra a unificación do idioma galego (Santiago: Nós).

Tato Fontaiña, L. (1999): Historia do teatro galego. Das orixes a 1936 (Vigo: A Nosa Terra).

Varela, I. (1989): La Universidad de Santiago (1900-36). Reforma universitaria y conflicto estudiantil (Sada / A Coruña: Ediciós do Castro). 
Villar Ponte, A.(1922): Almas Mortas. Novela Dialogada Cómico Tráxica, En Tres Estancias (Ferrol: Céltiga, $\mathrm{N}^{\circ} 3$ ).

Villar Ponte, A.(1924): "Palabras íntimas" en García Acuña, J.: El idearium regionalista (La Coruña: Ediciones de "El Noroeste"). 